\title{
Correspondence
}

\section{Effect of bucolome in preterm infants}

Sir,

Segni et al. (Archives, 1977, 52, 549) reported the prevention of hyperbilirubinaemia in premature infants by bucolome. The effect of bucolome on hyperbilirubinaemia in Gilbert's syndrome was well established by observation of about 30 cases of the syndrome(Yamamoto et al., 1974). However, as for the mechanism of the effect, we found that bucolome showed no induction of liver microsomal enzymes (Adachi and Yamamoto, 1976) but did show a strong tendency to dissociate bilirubin from serum albumin (Yamamoto and Adachi, 1974). This dissociation was shown in vivo in Gunn rats, and in vitro using human albumin and red cells.

We believe, therefore, that although bucolome is useful in cases of Gilbert's syndrome, it should not be further tried in premature infants.

\section{Toshio Yamamoto and \\ YUKIHIKO ADACHI \\ Department of Medicine, \\ Kinki University School of Medicine, Sayama-Cho, Minamikawachi-Gun, Osaka, Japan.}

\section{Dr. Romagnoli and co-workers comment:}

We are indebted to Drs Yamamoto and Adachi for their preciseness about the different mechanism of action of bucolome compared with phenobarbital in animals
(Yamamoto et al., 1974; Adachi and Yamamoto, 1976). However, our results suggest that the mechanism of serum bilirubin reduction induced by bucolome in man is different from the one reported by Yamamoto and by Semba in Gunn rats (Yamamoto and Adachi, 1974; Semba et al., 1975). In fact bucolome administration to Gunn rats reduces serum bilirubin rapidly, while our results show that bucolome does not reduce serum bilirubin significantly in newborn infants during the hours after oral administration; its effect is delayed for about $\mathbf{4 8}$ hours. Moreover, serum bilirubin continues to fall after discontinuation of treatment. Our results agree with those of Baba $(1972 / 73)$ in term newborns, and are not consistent with the hypothesis that the mechanism of action of bucolome in man is the displacement of bilirubin from the plasma compartment to the cellular one, as shown in Gunn rats.

We have studied the effect of bucolome on albuminbilirubin binding capacity in a group of 20 healthy newborn infants with nonhaemolytic jaundice in the first 5 days of life. The evaluation of albumin-bilirubin binding capacity was done by gel filtration technique (Kernlute test, Ameis-Yissum, Jerusalem, Israel) before and after oral administration of a single dose of $15 \mathrm{mg} / \mathrm{kg}$ bucolome corresponding to the dosage of $30 \mathrm{mg} / \mathrm{kg}$ per day that we used in our previous study. The results of the study are given in the Table.

Our experience does not absolutely exclude a reduction of albumin-bilirubin binding capacity caused by bucolome; nevertheless it shows that, if there is such a

Table

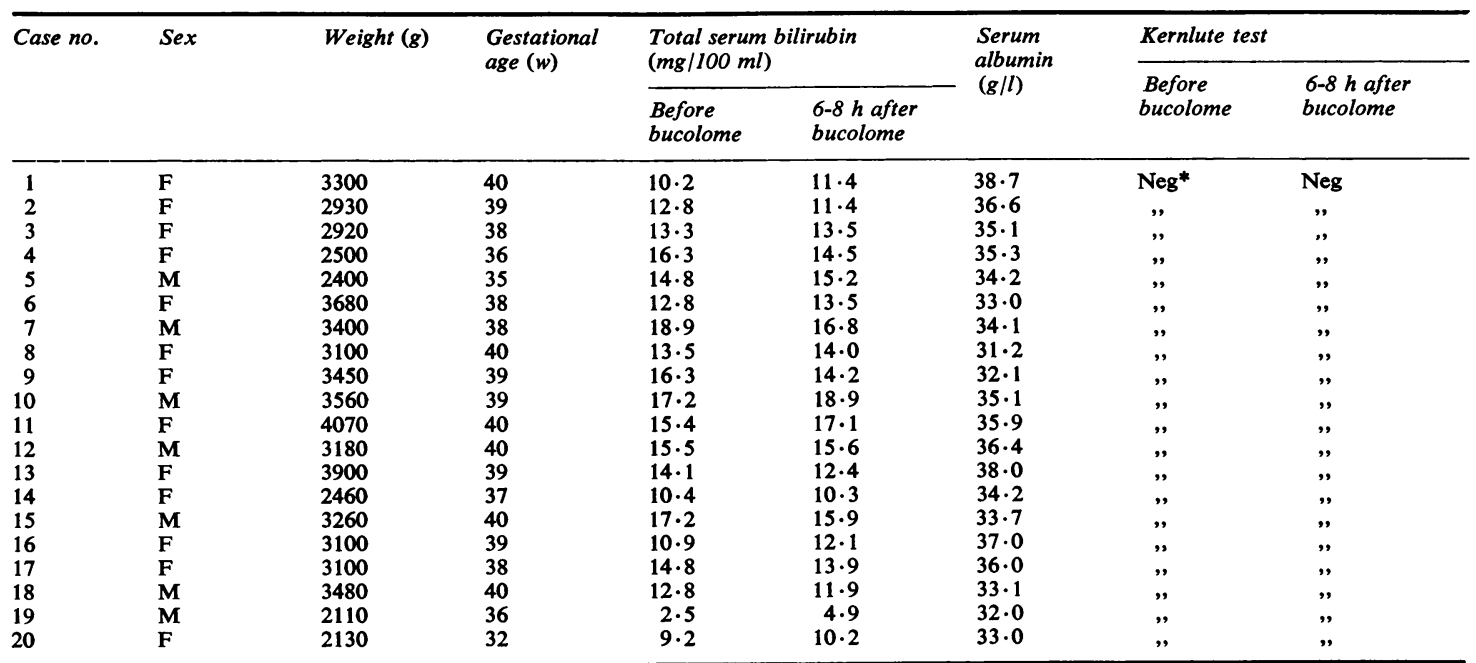

*Albumin-bilirubin binding capacity $>5 \mathrm{mg} / 100 \mathrm{ml}$.

Conversion: Traditional units to SI-Bilirubin: $1 \mathrm{mg} / 100 \mathrm{ml} \approx 17.1 \mu \mathrm{mol} / 1$. 
reduction, it is not clinically significant in our experimental conditions because the albumin-bilirubin binding capacity always remained greater than $5 \mathrm{mg} / 100 \mathrm{ml}$ in any case. Further, the babies included in our study are being followed-up; and we have not so far seen any significant neurological damage in infants treated with bucolome.

In conclusion we think that the mechanism of action of bucolome is not clear and needs further investigation in vivo. Meanwhile we consider that bucolome should not be used therapeutically in newborn infants with high levels of serum bilirubin because of the possibility of reduction in albumin-bilirubin binding capacity and because its effect is slow. On the contrary, in the prophylaxis of hyperbilirubinaemia bucolome should be used only when there is careful control of the albuminbilirubin binding capacity during treatment.

\section{G. Segni, G. Polidori, and C. Romagnoli Clinica Pediatrica, Università Cattolica S. Cuore, Largo A. Gemelli 8, 00168 Rome,} Italy.

\section{References}

Adachi, Y., and Yamamoto, T. (1976). Influence of drugs and chemicals upon hepatic enzymes and proteins. I. Structureactivity relationship between various barbiturates and microsomal enzyme induction in rat liver. Biochemical Pharmacology, 25, 663-668.

Baba, K. (1972/73). Use of bucolome in hyperbilirubinemia. Paediatrician, 1, 109-111.

Semba, R., Yamamura, H., Sato, H., and Murakami, U. (1975). Drug safety test in perinatal stage. Teratology, 12, 209-210.

Yamamoto, T., and Adachi, Y. (1974). On the mechanism of the effect of bucolome on unconjugated hyperbilirubinemia. Acta Hepatologica Japonica, 15, 607.

Yamamoto, T., Kosaka, K., Ichida, F., Kanetaka, T., Kameda, H., Namihisa, T., Takino, T., Hirayama, S., Tanikawa, K., Kondo, T., and Kuchiha, K. (1974). The studies of the effect of bucolome on jaundice of Gilbert's syndrome and Dubin-Johnson syndrome. Japanese Archives of Internal Medicine, 21, 427-437.

\section{Protracted diarrhoea in infancy}

Sir,

We read with great interest the article by Larcher $e t$ al. (Archives, 1977, 52, 597) and would like to comment on several points. The authors included patients diagnosed as having secondary disaccharide intolerance in category 1 , those with a specific diagnosis. Secondary disaccharide intolerance, as its name implies, is secondary to an insult which causes small intestinal mucosal damage with secondary disaccharidase deficiency. We think that this entity should be included in category 2 where no cause for the diarrhoea could be established.

In the past year we have treated 14 infants with a diagnosis of protracted diarrhoea in infancy. The diagnosis was made according to the criteria of Avery et al. (1968) with modification regarding the age of the patient. All had variable disaccharidase deficiencies, documented by specific enzyme assays done on jejunal biopsy material. We believe that if more patients in category 2 had had jejunal biopsies and disaccharidase activity determination, the number with secondary disaccharidase deficiencies (made apparent with appropriate tolerance tests) would be far greater than was found by Larcher et al.

The small intestinal biopsy is an important tool in diagnosis as well as in determining modes of treatment; namely, parenteral hyperalimentation versus some modification of an elemental diet (Branski, 1978).

D. BRANSKI,

T. F. HATCH, and

E. LEBENTHAL

Division of Gastroenterology, Department of Pediatrics, Children's Hospital of Buffalo, Buffalo, NY 14222, USA.

\section{References}

Avery, G. B., Villavicencio, O., Lilly, J. R., and Randolph, J. G. (1968). Intractable diarrhoea in early infancy. Pediatrics, 41, 712-722.

Branski, D. (1978). Intractable diarrhoea of infancy. Digestive Diseases in Children. Ed. by $\mathrm{E}$. Lebenthal. Grune and Stratton, New York.

\section{Dr Larcher and co-workers comment:}

We welcome the letter of Drs Branski, Hatch, and Lebenthal. In the main they comment on two important issues. We agree, of course, that clinical intolerance to disaccharides may be a primary or secondary phenomenon, and that it can be related to a variety of pathophysiological events. We assumed that this would be evident to readers when categorising our patients.

Clinical intolerance to disaccharides is not synonymous with the in vitro activity of the substrate-specific enzyme activity assayed in intestinal biopsies obtained from the proximal small gut. Hydrolysis of ingested oligosaccharides is an extremely efficient physiological process, and clinical intolerance of ingested oligosaccharides will only occur when there is extensive reduction in the brush border membrane activity of disaccharidases. In clinical practice the important issue is whether ingested sugars provoke gastrointestinal symptoms, not what the activity of a particular enzyme is in an in vitro laboratory assay system. Our category 2 patients did not clinically respond to elimination of disaccharides from their diets. This does not necessarily imply that they were not intolerant to disaccharides, but does indicate that other pathophysiological factors were operating in the genesis of the protracted diarrhoea.

We also agree that small intestinal biopsy can be a very useful procedure in the diagnosis and management of protracted diarrhoea in infancy. It should be stressed, however, that a biopsy is not mandatory to the diagnosis and management of very sick infants with protracted diarrhoea, and that an empirical approach based on currently available knowledge is sometimes unavoidable. The procedure is not without risk in severely malnourished infants such as those reported in our publication. Unfortunately a detailed diagnostic work-up is not always 